\title{
Body dimension measurements for pillow design for Taiwanese
}

\author{
Hsiao-Lin Chen ${ }^{\mathrm{a}}$ and Dengchuan $\mathrm{Cai}^{\mathrm{b}}$ \\ ${ }^{a}$ Graduate School of Design Doctoral Program, National Yunlin University of Science and Technology, Yunlin \\ 64002, Taiwan, R.O.C.e-mail: g9930816@yuntech.edu.tw \\ ${ }^{\mathrm{b}}$ Department of Industrial Design, National Yunlin University of Science and Technology, Yunlin, 64002, Taiwan, \\ R.O.C.e-mail:caidc@yuntech.edu.tw
}

\begin{abstract}
Study reported a pillow with a uniform height was not suitable for sleeping in supine and lateral positions. The study aims to determine the pillow dimensions for fitting supine and lateral positions for Taiwanese. Ten females and ten males subjects with a mean age of 21.9 years $(\mathrm{SD}=1.07$ years) participated in the study. Body dimensions of head, neck and shoulder in crown and sagittal planes were measured with the Martins' anthropometer and a curve measurer to determine the pillow's sizes. The results showed that the basic form of pillow for both genders is a $\mathrm{U}$ form from the front view. The middle area of the pillow is for supine position and the both side areas are for lateral positions. The base of pillow is a rectangle from the top view. The pillow is designed with a width of 75 and $70 \mathrm{~cm}$ for male and female, and a depth of 40 and $35 \mathrm{~cm}$ for male and female. The height in middle area and both side are 4 and $14 \mathrm{~cm}$ for male, and 2 and $12 \mathrm{~cm}$ for female. A neck rest with a height of $1.5 \mathrm{~cm}$ was proposed for neck support.
\end{abstract}

Keywords: pillow design; sleep posture; anthropometry.

\section{Introduction}

Human beings spend one-third of life for sleeping. It occupies twenty-four years to an average life span of 72 years old. High quality and sufficient sleep is essential and required to the human. The function of sleep is similar to water, air and foods to human body. Sleep regulates daily living and the cognitive ability, judgment, and memory that are needed at work. . It maintains the human physiological functions and biological processes [1] . Kyle, Morgan, and Espie [2] pointed out that the quality of sleep is directly related to the human health as well as living standards.
Sleep posture also affects physical health. Leung Bowman, Parker, Newton, Douglas Bradley [3] concluded that to avoid abnormal cardiac functions due to external pressure, one should avoid the left lateral position. This is especially important for patients suffering from congestive heart failure. In addition, related research [4-7] reported that shoulder pain is a common musculoskeletal disorders. If unsuitable bedding is used, neck and shoulder muscles are likely to develop disorder symptoms . Research by Lavin, Pappagallo, and Kuhlemeier [8] suggested that using a suitable pillow can significantly reduce neck and shoulder pain. 
Using a suitable pillow to have appropriate support on the head to maintain a natural curvature of the spine during the sleep can get a high quality sleep. There are many pillows in the market that were designed based on the shape of head and neck. They are supposed to increase the contact area between the neck and the pillow such that the pressure exerted upon muscles can be evenly distributed. This is workable for a fixed posture. However, people always changed their postures during sleep. Generally, two postures: supine and lateral positions were common used.

Study [9] have been concluded that a pillow designed with an uniform height is not being able to fit both supine position and lateral position during sleep. From the point of view on body dimension measurements, it is easy to understand that the distance from one's ear to shoulder in the crown plane is longer than the distance from one's hindbrain to the upper back in the sagittal plane. More, the results of observation [9] pointed out, when using the pillow in current markets for sleeping in the supine position, the front neck and throat of participants were bent and pressed. However, sleeping in the lateral position, the upper arm and shoulder of participants were pressed and the neck in upper side were bent extension. This means that the current pillow in markets is too high for people sleeping in supine position and is too low in lateral position. In order to provide a reference for the pillow design, this study aims to investigate the changes of postures during sleep.

\section{Methods}

\subsection{Subjects}

Twenty students (10 females and 10 males) served as subjects participating in the study aging from 20 to 28 years with a mean age of 22.8 years $(\mathrm{SD}=1.3$ years). The mean stature of male and female are $175.07 \mathrm{~cm}(\mathrm{SD}=6.38)$ and $158.55 \mathrm{~cm}(\mathrm{SD}=5.28)$, respectively. The mea weight of male and female are $68.96 \mathrm{~kg}(\mathrm{SD}=9.71)$ and $51.94 \mathrm{~kg}(\mathrm{SD}=7.09)$, respectively.

\subsection{Measurements and apparatus}

The measurements of body dimension of Taiwanese subjects were measured in the standard posture were measured to determining the pillow's dimensions. The definitions of measurements are illustrated in Figure 1, Figure 2 and Table 1. There are two main experimental instruments in the study. One of them was a set of Martin's anthropometric measuring instrument, including stature gauge, beam callipers, slide callipers, outside callipers, tape measure, and ruler. The other instrument was a body-curve measurer made by the study. 


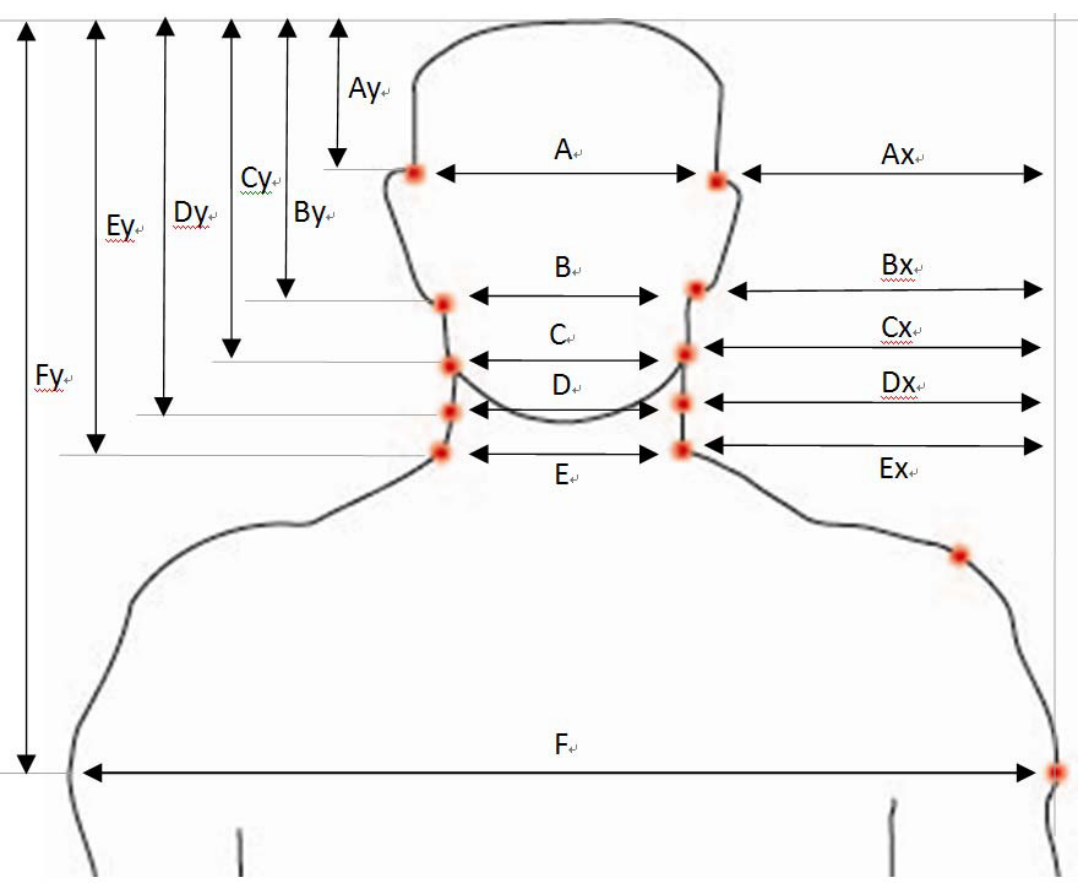

Figure 1. Illustration of body dimension measurements in crown plane

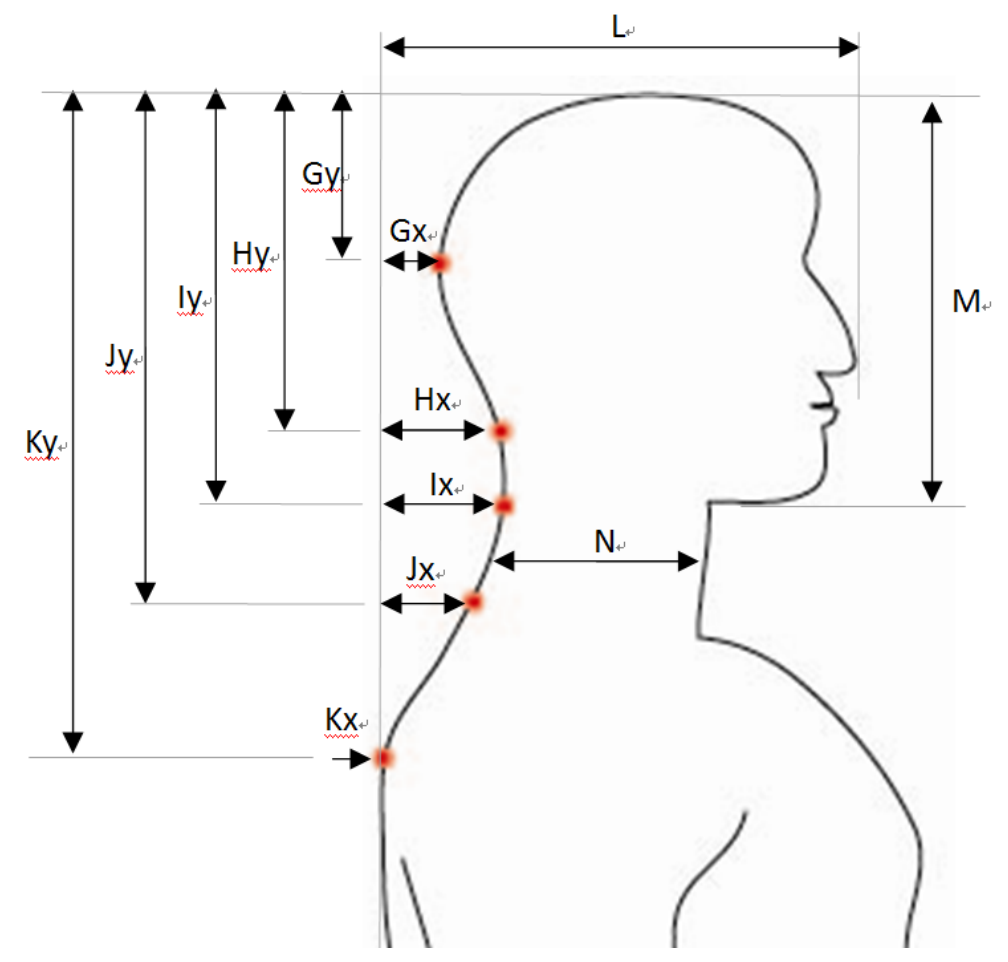

Figure 2. Illustration of body dimension measurements in sagittal plane 


\subsection{Experimented procedure}

The experiment was conducted in an ergonomic laboratory at university. First, the researchers explained the experimental goals and guidelines to the subjects. Then, the subjects were measured for the several anthropometric dimensions (Table 1 and Table 2). Finally, measurements of the body dimensions were recorded.

\section{Results and discussions}

The statistics of body dimension measurements of the male subjects showed in Table 1. Table 1 listed the minimum, maximum, mean, and standard deviation. The stature and weight of the male are 175 $\mathrm{cm}$ and $69 \mathrm{~kg}$. This is similar to the Taiwanese stature $(171.70 \mathrm{~cm})$ and weight $(64.93 \mathrm{~kg})$ measured by Wang, Wang and Lin (2002). The width from ear to shoulder is $14.26 \mathrm{~cm}[(13.46+14.76) / 2]$ and the width from neck to shoulder is $15.69 \mathrm{~cm}[(15.79+15.94+$ 15.36)/3]. Whereas, the length from hindbrain to wall is $3.68 \mathrm{~cm}$, and the length from neck to wall is 4.98 $\mathrm{cm}[(5.53+5.69+3.71) / 3]$. The difference between the width from ear to shoulder and the length from hindbrain to wall is $10.58 \mathrm{~cm}$, and difference between the width from neck to shoulder is and the length from neck to wall is $10.71 \mathrm{~cm}$. This illustrated a difference of $10.5 \mathrm{~cm}$ from head to bed surface in crown plane and in sagittal plane. That means the pillow height for supine position and for lateral position should be different with a difference of $10.5 \mathrm{~cm}$. The difference between head and neck in crown plane and in sagittal plane are $1.43 \mathrm{~cm} \mathrm{(15.69-14.26)} \mathrm{and} 1.3 \mathrm{~cm}$ (4.98-3.68), respectively.

Table 2 showed the statistics of body dimension measurements of the female subjects. The Table illustrated the minimum, maximum, mean, and standard deviation. The stature and weight of the female are $158.55 \mathrm{~cm}$ and $51.94 \mathrm{~kg}$. This is similar to the Taiwanese stature $(150.97 \mathrm{~cm})$ and weight $(51.97$ $\mathrm{kg}$ ) measured by Wang, Wang and Lin (2002). The width from ear to shoulder is $11.97 \mathrm{~cm}[(11.39+$ $12.55) / 2$ ] and the width from neck to shoulder is 13.98 $\mathrm{cm}[(14.00+14.31+13.64) / 3]$. Whereas, the length from hindbrain to wall is $1.44 \mathrm{~cm}$, and the length from neck to wall is $2.79 \mathrm{~cm}[(2.94+3.37+2.06) / 3]$. The difference between the width from ear to shoulder and the length from hindbrain to wall is $10.53 \mathrm{~cm}$, and difference between the width from neck to shoulder is and the length from neck to wall is $11.19 \mathrm{~cm}$. That means the pillow height for supine position and for lateral position should be different with a difference about 10.5-11.2 $\mathrm{cm}$. The difference between head and neck in crown plane and in sagittal plane are $2.01 \mathrm{~cm}$ (13.98-11.97) and $1.35 \mathrm{~cm}(2.79-1.44)$, respectively.

\section{Pillow dimension design}

According to the analytical results, we can get the guidelines for pillow design as following: (1) the pillow dimension for male and female should be different and need to build respectively. (2) the pillow height for supine position and for lateral position should be different with a difference of about $10.5 \mathrm{~cm}$. 
Table 1.

Body dimension measurement of male

\begin{tabular}{|c|c|c|c|c|c|}
\hline Body dimensions & $\mathrm{N}$ & Min & Max & Mean & SD. \\
\hline Age & 10 & 24 & 21 & 22.10 & 1.10 \\
\hline Stature & 10 & 165.0 & 186.5 & 175.07 & 6.38 \\
\hline Weight & 10 & 48.0 & 83.0 & 68.96 & 9.71 \\
\hline A, Head breadth at upper edge of ear (otobasion) & 10 & 15.2 & 16.6 & 15.80 & .45 \\
\hline B, Head breadth at lower edge of ear (bitragion) & 10 & 13.0 & 14.5 & 13.79 & .49 \\
\hline $\mathrm{C}$, Neck breadth at upper edge of neck & 10 & 11.0 & 12.3 & 11.74 & .41 \\
\hline $\mathrm{D}$, Neck breadth at middle neck & 10 & 10.8 & 12.2 & 11.43 & .43 \\
\hline E, Neck breadth at lower edge of neck & 10 & 11.7 & 14.3 & 12.60 & .83 \\
\hline F, Shoulder breadth maximum & 10 & 40.0 & 47.0 & 43.31 & 2.38 \\
\hline Ax, Width from upper edge of ear to shoulder & 10 & 12.3 & 15.5 & 13.76 & 1.07 \\
\hline Bx, Width from lower edge of ear to shoulder & 10 & 13.1 & 16.4 & 14.76 & 1.14 \\
\hline $\mathrm{Cx}$, Width from upper edge of neck to shoulder & 10 & 14.3 & 17.6 & 15.79 & 1.11 \\
\hline Dx, Width from middle neck to shoulder & 10 & 14.5 & 17.6 & 15.94 & 1.06 \\
\hline Ex, Width from lower edge of neck to shoulder & 10 & 14.0 & 17.1 & 15.36 & 1.07 \\
\hline Ay, Height from upper edge of ear to vertex & 10 & 11.1 & 15.1 & 13.46 & 1.34 \\
\hline By, Height from lower edge of ear to vertex & 10 & 17.1 & 20.7 & 19.03 & 1.20 \\
\hline $\mathrm{Cy}$, Height from upper edge of neck to vertex & 10 & 19.0 & 25.5 & 21.27 & 1.88 \\
\hline Dy, Height from middle neck to vertex & 10 & 22.5 & 28.7 & 24.77 & 1.95 \\
\hline Ey, Height from lower edge of neck to vertex & 10 & 26.3 & 31.0 & 29.15 & 1.49 \\
\hline Fy, Height from shoulder to vertex & 10 & 33.4 & 41.4 & 35.98 & 2.23 \\
\hline Gx, Length from hindbrain to wall & 10 & .3 & 6.4 & 3.68 & 2.20 \\
\hline Hx, Length from upper edge of neck to wall & 10 & 2.0 & 7.5 & 5.53 & 1.74 \\
\hline Ix, Length from middle neck to wall & 10 & 2.7 & 7.0 & 5.69 & 1.36 \\
\hline $\mathrm{Jx}_{\mathrm{x}}$ Length from lower edge of neck to wall & 10 & 1.4 & 6.5 & 3.71 & 1.61 \\
\hline Gy, Height from hindbrain to vertex & 10 & 10.0 & 14.8 & 12.32 & 1.59 \\
\hline Hy, Height from upper edge of neck to vertex & 10 & 16.6 & 21.0 & 18.17 & 1.48 \\
\hline Iy, Height from middle neck to vertex & 10 & 21.4 & 25.3 & 22.87 & 1.25 \\
\hline Jy, Height from lower edge of neck to vertex & 10 & 25.2 & 31.2 & 28.05 & 1.88 \\
\hline Ky, Height from upper back to vertex & 10 & 35.0 & 43.3 & 39.90 & 2.88 \\
\hline L, Head length (pronasale to hindbrain) & 10 & 16.8 & 21.7 & 19.79 & 1.38 \\
\hline M, Head height (menton to vertex) & 10 & 19.9 & 27.1 & 23.10 & 2.21 \\
\hline $\mathrm{N}$, Neck length & 10 & 10.4 & 12.6 & 11.63 & .68 \\
\hline
\end{tabular}


Table 2 .

Body dimension measurement of female

\begin{tabular}{|c|c|c|c|c|c|}
\hline Body dimensions & $\mathrm{N}$ & Min & Max & Mean & SD. \\
\hline Age & 10 & 21 & 24 & 21.7 & 1.06 \\
\hline Stature & 10 & 152.8 & 169.4 & 158.55 & 5.28 \\
\hline Weight & 10 & 41.7 & 70.0 & 51.94 & 7.92 \\
\hline A, Head breadth at upper edge of ear (otobasion) & 10 & 14.3 & 17.4 & 15.39 & .82 \\
\hline B, Head breadth at lower edge of ear (bitragion) & 10 & 11.5 & 14.1 & 13.06 & .75 \\
\hline C, Neck breadth at upper edge of neck & 10 & 9.2 & 11.9 & 10.16 & .95 \\
\hline $\mathrm{D}$, Neck breadth at middle neck & 10 & 8.8 & 10.6 & 9.55 & .62 \\
\hline E, Neck breadth at lower edge of neck & 10 & 9.9 & 12.0 & 10.89 & .75 \\
\hline F, Shoulder breadth maximum & 10 & 36.9 & 40.7 & 38.16 & 1.45 \\
\hline Ax, Width from upper edge of ear to shoulder & 10 & 10.8 & 12.6 & 11.39 & .65 \\
\hline Bx, Width from lower edge of ear to shoulder & 10 & 11.9 & 13.7 & 12.55 & .63 \\
\hline Cx, Width from upper edge of neck to shoulder & 10 & 13.1 & 15.7 & 14.00 & .72 \\
\hline Dx, Width from middle neck to shoulder & 10 & 13.6 & 15.9 & 14.31 & .71 \\
\hline Ex, Width from lower edge of neck to shoulder & 10 & 13.0 & 15.2 & 13.64 & .72 \\
\hline Ay, Height from upper edge of ear to vertex & 10 & 11.4 & 13.3 & 12.15 & .66 \\
\hline By, Height from lower edge of ear to vertex & 10 & 16.5 & 19.3 & 17.58 & .89 \\
\hline Cy, Height from upper edge of neck to vertex & 10 & 18.6 & 21.6 & 19.79 & 1.07 \\
\hline Dy, Height from middle neck to vertex & 10 & 21.5 & 25.0 & 22.82 & 1.14 \\
\hline Ey, Height from lower edge of neck to vertex & 10 & 24.8 & 28.2 & 26.77 & 1.16 \\
\hline Fy, Height from shoulder to vertex & 10 & 29.5 & 33.6 & 31.47 & 1.43 \\
\hline Gx, Length from hindbrain to wall & 10 & .3 & 4.3 & 1.44 & 1.50 \\
\hline Hx, Length from upper edge of neck to wall & 10 & .5 & 5.8 & 2.94 & 1.79 \\
\hline Ix, Length from middle neck to wall & 10 & 9 & 5.8 & 3.37 & 1.54 \\
\hline Jx, Length from lower edge of neck to wall & 10 & .4 & 4.0 & 2.06 & 1.20 \\
\hline Gy, Height from hindbrain to vertex & 10 & 9.2 & 15.2 & 11.06 & 1.76 \\
\hline Hy, Height from upper edge of neck to vertex & 10 & 16.1 & 19.4 & 17.74 & 1.09 \\
\hline Iy, Height from middle neck to vertex & 10 & 20.1 & 26.2 & 22.08 & 1.82 \\
\hline Jy, Height from lower edge of neck to vertex & 10 & 25.2 & 32.4 & 27.09 & 2.11 \\
\hline Ky, Height from upper back to vertex & 10 & 37.1 & 40.4 & 38.51 & 1.08 \\
\hline L, Head length (pronasale to hindbrain) & 10 & 18.5 & 20.8 & 19.36 & .66 \\
\hline M, Head height (menton to vertex) & 10 & 18.5 & 23.4 & 20.94 & 1.52 \\
\hline $\mathrm{N}$, Neck length & 10 & 8.8 & 10.0 & 9.26 & .44 \\
\hline
\end{tabular}




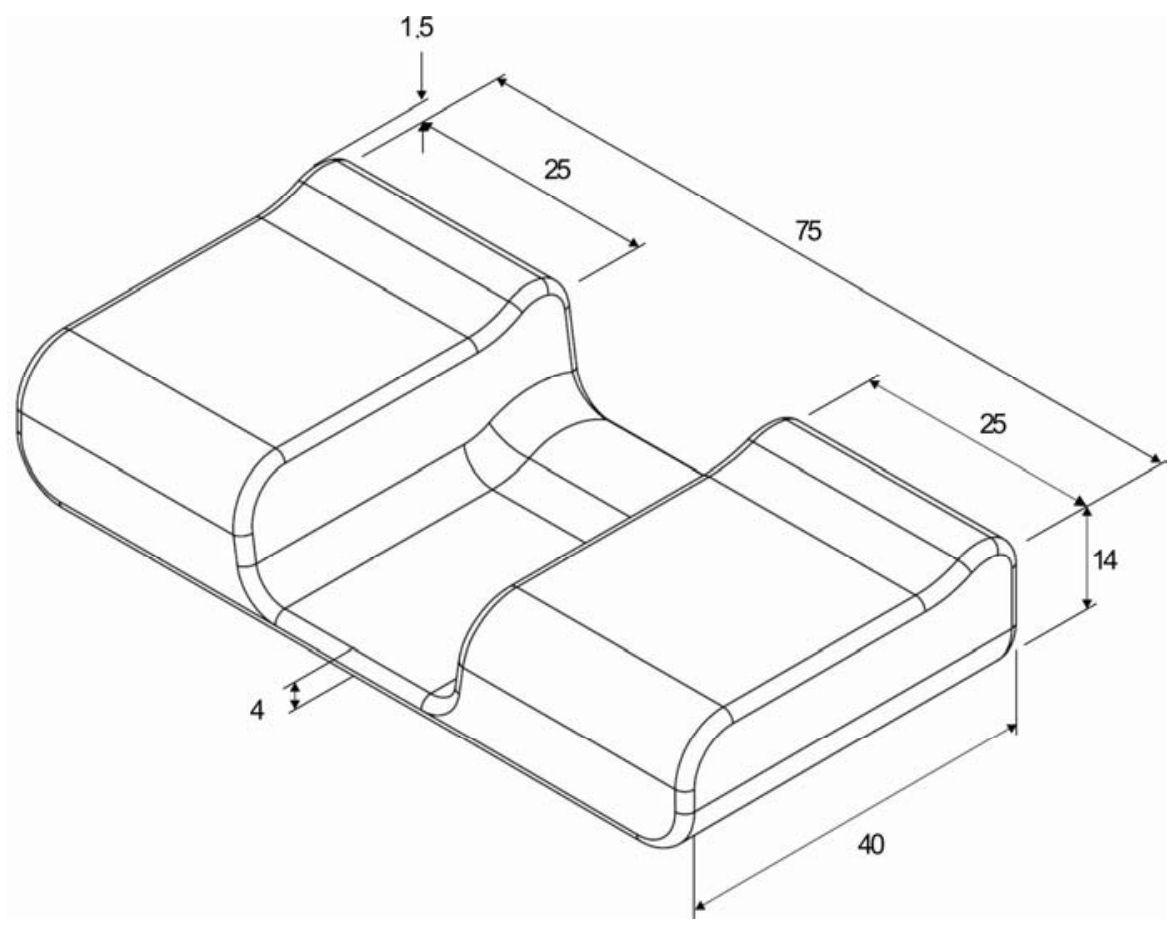

Figure 3. The pillow dimensions for young male

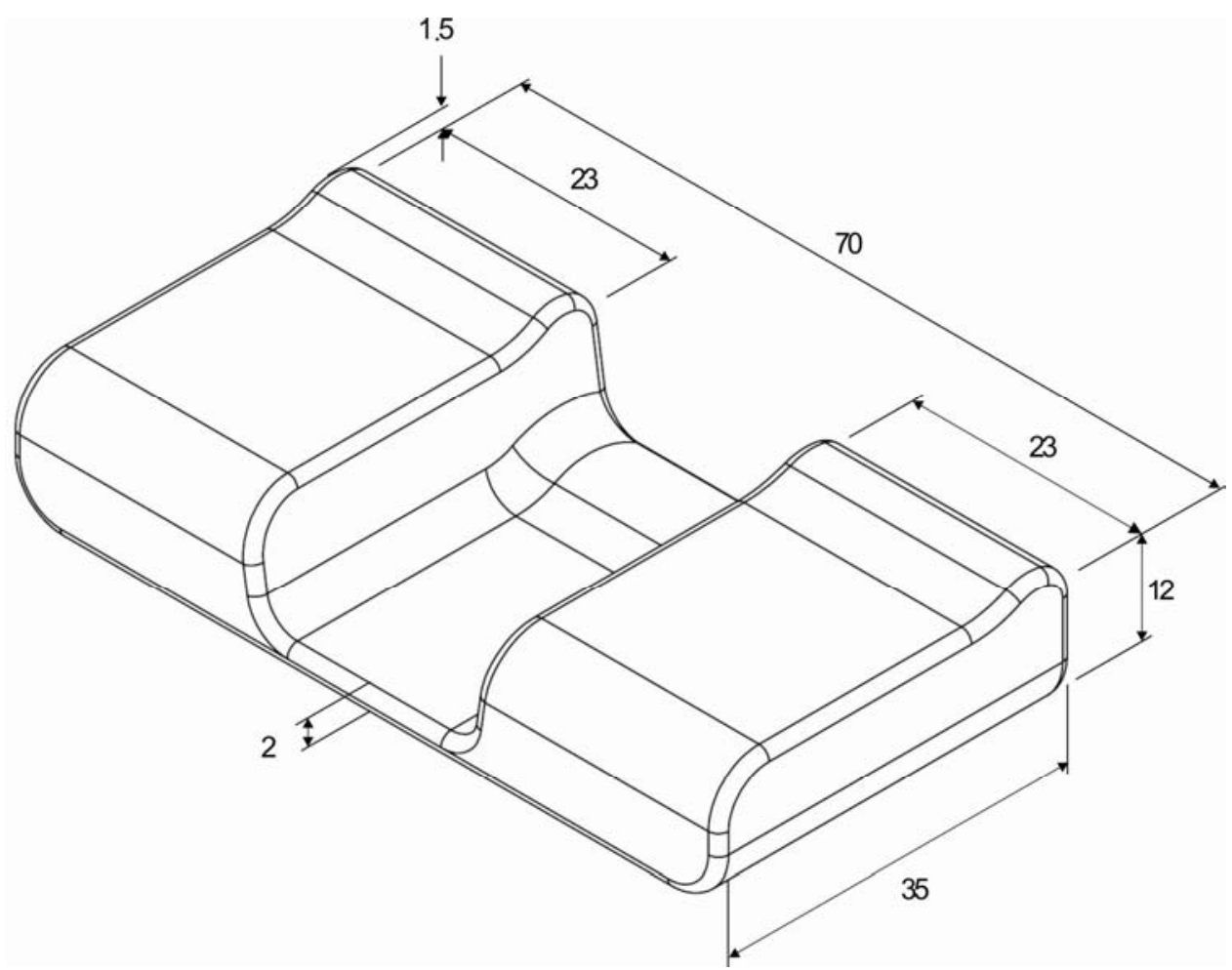

Figure 4. The pillow dimensions for young female 
(3) the pillow width should be equal to shoulder breath + head length + allowance. (4) the pillow depth should be equal to the height from shoulder to vertex + allowance. (5) A neck rest with about $1.5 \mathrm{~cm}$ should be proposed for pillow design for neck support during sleep. The dimensions of the pillow for male and female were showed in the Figure 3 and Figure 4, respectively.

\section{Conclusions and suggestions}

The study aims to determine the dimension for pillow design for Taiwanese. From the measurements of the body dimension and anthropometric data analysis, and the pillow design, we can get two pillow models for male and female. The basic form of the pillow for both genders is a $\mathrm{U}$ form from the front view. The pillow height of middle area is lower and that of both sides are higher. The middle area of the pillow is for supine position and the both side areas are for lateral position. Each area shared one third of pillow width. A neck rest with $1.5 \mathrm{~cm}$ of height is proposed to pillow design for neck support during sleep. The results showed that the dimensions of pillow for female and male are different. For male, the form of the base of pillow is a rectangle with a width of $75 \mathrm{~cm}$ and a depth of $40 \mathrm{~cm}$ from the top view. The height of middle area and both side are $4 \mathrm{~cm}$ and 14 $\mathrm{cm}$, respectively. For female, the form of the base of pillow is a rectangle with a width of $70 \mathrm{~cm}$ and a depth of $35 \mathrm{~cm}$ from the top view. The height of middle area and both side are $2 \mathrm{~cm}$ and $12 \mathrm{~cm}$, respectively.

\section{Reference}

[1] T.C.B. Schutz, M.L. Andersen, S Tufik, The influence of orofacial pain on sleep pattern: A review of theory animal models a nd future directions. Sleep Medicine, 2009, 10, 822-828.

[2] S.D. Kyle, K Morgan, C.A. Espie, Insomnia and health-related quality of life. Sleep Medicine Reviews, 2010, $14,69-82$.

[3] R.S.T. Leung, M.E. Bowman, J.D. Parker, G.E. Newton, T.D. Bradley, Avoidance of the left lateral decubitus position during sleep in patients with heart failure: relationship to cardiac size and function. Journal of the American College of Cardiology, 2003, 41, 227-230.

[4] R.P. Bonafede, R. M. Bennett, Shoulder pain Guidelines to diagnosis and management. Postgraduate Med, 1987, 82:1, 85-93.

[5] D.A.W.M. Van Der Windt, B.W. Koes, A. Jong, L.M. Bouter, Shoulder disorders in genneral practice. Incidence, patient characteristics and management. Ann Rheumat Dis, $1999,54: 9,59-64$.

[6] L.S. Cunnigham , J.L. Kelsey, Epidemiology of musculoskeletal impairments and associated disability. Am J Pub Health, 1984,74:574-9.

[7] J.P. Belzer, R.C. Durkin, Common disorders of the shoulder. Prim Care, 1996, 23:3, 65-88.

[8] R.A. Lavin, M. Pappagallo, K.V. Kuhlemeier. Cervical pain: a comparison of three pillows. Archives of Physical Medicine and Rehabilitation, 1997, 78, 193-8.

[9] D. Cai, H. L.Chen, Sleep position analysis for Taiwanese, Research project report. National Yunlin University of Science and Technology, Taiwan, 2011. 